\title{
BIBECHANA
}

A Multidisciplinary Journal of Science, Technology and Mathematics ISSN 2091-0762 (Print), 2382-5340 (Online)

Journal homepage: http://nepjol.info/index.php/BIBECHANA

Publisher: Research Council of Science and Technology, Biratnagar, Nepal

\section{Anxiety and depression among adolescent students at higher secondary school}

\author{
M. Bhandari \\ Faculty of Child Health Nursing, Tribhuwan University, Institute of Medicine, Nursing Campus \\ Biratnagar, Nepal \\ *E-mail: menukamenu@gmail.com \\ Article history: Received 6 November, 2016; Accepted 15 November, 2016 \\ DOI: http://dx.doi.org/10.3126/bibechana.v14i0.16019 \\ This work is licensed under the Creative Commons CC BY-NC License. \\ https://creativecommons.org/licenses/by-nc/4.0/ \\ (c) (i) (8)
}

BY

\section{Abstract}

This study was conducted to assess the association of depression and anxiety with selected variables; low academic performance and poor parent adolescent relationship among the adolescent students at Arniko Higher Secondary school at Biratnagar. Beck Depression Inventory (BDI) and Beck Anxiety Inventory (BAI) tools were used for data collection. Spearman's Rank Correlation Coefficient and Chi Square test were applied to assess the significant variables. The findings of the study revealed that there was significant correlation between total depression and total anxiety score i.e. Spearman's rank correlation coefficient value was $0.554(\mathrm{p}=0.000)$. The study also found that the depression and anxiety were significantly associated with type of family $(p=0.005 \& p=0.015)$. The depression was significantly associated with academic performance of adolescent students $(p=0.030)$ and major accident in the family ( $p=0.009$ ). Similarly, the anxiety was significantly associated with parental fight $(p=0.007)$, conflict with father $(p=0.019)$, and death of family member $(p=0.016)$. It can be concluded that adolescent anxiety and depression are significant mental health problems so further studies are needed to validate the findings.

Keywords: Depression; Anxiety; adolescent student; correlation; Higher Secondary School.

\section{Introduction}

The term "adolescence" comes from the Latin word adolescence, which means, "to grow into adulthood". It has illustrated it begins with the onset of puberty and ends with the assumption of adult responsibilities; as one philosopher remarked, adolescence begins in biology and ends in culture as stated by Laufer [1]. Adolescence has been defined by World Health Organization (WHO) as the period of life spanning the 
ages between 10 and 19 years. Adolescence is a crucial phase in life and the presence of conditions like depression and anxiety at this stage of life is a matter of concern.

A study conducted by Mayne R.G. has highlighted that mental health problems can develop at any point in life and may be influenced by a variety of factors, including genetics or family history of a disorder, chemical imbalances in the brain, or stressors in the environment [2]. World Health Organization [3] reported the increase in mental health problems such as depression, anxiety and suicide rate may reflect the difficulties that some adolescents face as they encounter the cognitive, physical, psychological and spiritual changes that accompany during puberty. Epidemiological studies suggest that the Comorbidity is much higher, thus suggesting an intimate connection between them where the presence of one increases the likelihood of the other occurring.

Anxiety disorders typically onset in childhood and adolescence and run a chronic course well into adulthood according to a study conducted by Albano, Chorpita \& Barlow [4]. In the United States, prevalence studies of childhood and adolescent anxiety disorders in the general population have yielded overall rates of between 17 and $21 \%$ as reported by Kashani \& Orvaschel [5]. Essau et al. [6] concluded that anxiety is associated with substantial negative effects on children's social, emotional and academic success. In the same way Major depressive disorder (MDD) often has an onset in adolescence, across diverse countries, and is associated with substantial psychosocial impairment and risk of suicide, Weiss \& Last's study suggested [7]. The incidence of Major Depressive Disorder is estimated to be approximately $5-8 \%$ in adolescents. One of the study conducted by Hughes showed that adolescent girls are twice as likely as adolescent boys to experience depression [8].

\section{Objectives of the study}

\section{General Objective:}

The general objective of this research was to assess the association of depression and anxiety with selected variables.

\section{Specific Objectives:}

- To assess the depression level of adolescents students.

- To assess the anxiety level of adolescents students.

- To correlate the depression and anxiety scores of adolescents students.

- To assess the association of depression and anxiety scores with selected variables.

\section{Hypotheses}

○ There is a positive relationship between depression and anxiety scores of adolescent students.

- There is a significant association between depression and anxiety level of adolescent students with low academic performance.

- The depression and anxiety level of adolescent students are significantly associated with poor parent - adolescent relationship. 


\section{Methods}

The study adopted Descriptive Correlational research design to find out the degree of association between depression and anxiety of adolescent and the association of selected variables with depression and anxiety level during the same period of time. The study was conducted at Arniko Higher Secondary School which is located in Biratnagar Municipality of Morang District. The study period was from July, 2014 to January, 2015. Formal permission for the study was taken from the ethical committee and written Permission was obtained from Arniko Higher Secondary School. Informed consent was taken from the respondents verbally. Objectives of the study were clearly explained to the respondents before data collection. The study population was all the adolescent students who were studying in class 12 in Science faculty at Arniko Higher Secondary School at Biratnagar. There were 300 students in class Twelve. The study adopted probability sampling technique, sample was selected following simple random, lottery method; required number 100 was selected among male and female students (50/50). Confidentiality of all the collected information was maintained throughout the study.

In keeping objectives of the study in mind, the following tools were selected: Part I: Semi- Structured Bio-Demographic Performa with selected variables, Part II: Beck Anxiety Inventory (BAI), Part III: Beck Depression Inventory (BDI). The selected variables were academic performance of students, parentadolescent relationship and adverse events in family in the last one year. Beck Anxiety Inventory (BAI) was developed by Aaron T. Beck and his colleagues is a 21 item self-rated questionnaire that describes common symptoms of anxiety. The subject has to rate how much he/she has been bothered by each symptom during the past one week on a 4 point scale ranging from $0-3$. This scale has a reliability value of $0.92 \&$ a validity that ranges from $0.82-0.87$. Since the scale is considered as a standard tool to measure anxiety symptoms. Scores will have implications for both in measuring severity and assessing changes in symptoms due to intervention [9]. Beck Depression Inventory (BDI) developed by Aaron T.Beck and his colleagues, is a 21 item self-rated questionnaire that describes common symptoms of depression. The subject has to rate according to how much he/she has been feeling during the past two

weeks on a 4 point scale ranging from $0-3$. The tool is considered as a standard scale for measuring severity of the depressive symptoms \& assessing the changes in the symptoms due to intervention. This scale has a reliability value ranging from 0.76 to 0.95 in psychiatric samples \& 0.73 to 0.92 in non psychiatric samples [10].

For descriptive analysis, mean, standard deviation, and median was calculated. To find out the correlation between depression and anxiety scores, Spearman's rank correlation coefficient was calculated and to find out the association with selected variables, chi square test was applied. The Beck Anxiety Inventory score of students was categorized as no anxiety (0-21), mild anxiety (22-32), moderate anxiety (33-48) \& severe anxiety (49-63). Similarly Beck Depression Inventory scored and cases were categorized as no depression (0-9), mild depression (10-19), moderate depression (20-29) \& severe depression (30-63).

\section{Results}

The age group was homogeneous, the caste distribution showed the representation of Brahmin was high i.e. $40 \%$ then others, the overall representation of Hindus and others were $98 \%$ and $2 \%$ respectively. 
Most of the respondents' father's educational status was graduation above i.e. $51 \%$ and mother's educational status was intermediate level i.e. 38\%. The Thirty six percentage respondents were from the higher family income group and $11 \%$ from low family income group. The major occupation of fathers of respondents was government job and the most of the respondents' mothers were housewife. The $64 \%$ of the students were hail from nuclear families shows the growing trend away from joint families, especially in urban areas.

Regarding the socio-demographic variables, it was found significant association between type of family and anxiety and depression of respondents $(\mathrm{p}=0.015)$ and $(\mathrm{p}=0.005)$ at $95 \%$ of confidence interval i.e. the anxiety and depression level of respondent was high in single parent family then joint and nuclear family.

Table 1: Anxiety Level of Respondents.

\begin{tabular}{lc} 
& $\mathbf{n}=\mathbf{1 0}$ \\
\hline Anxiety Level & Respondents \\
\hline None & 90 \\
Mild Anxiety & 10 \\
\hline
\end{tabular}

This study showed the $90 \%$ respondents had no anxiety and only $10 \%$ respondents had mild anxiety out of 100 respondents (Table 1)

Table 2: Depression Level of Respondents.

\begin{tabular}{|c|c|c|}
\hline & & $\mathrm{n}=\mathbf{1 0 0}$ \\
\hline Depression Level & Respondents & \\
\hline None & 24 & \\
\hline Mild & 59 & \\
\hline Moderate & 14 & \\
\hline Severe & 3 & \\
\hline
\end{tabular}

This study showed the $59 \%$ respondents had mild depression, $14 \%$ respondents had moderate depression, $3 \%$ had severe depression \& only $24 \%$ had no depression out of 100 respondents. (Table 2 )

Table 3: Association between Depression and Academic Performance.

\begin{tabular}{llccc}
\hline \multicolumn{1}{c}{ Academic Score } & \multicolumn{2}{c}{ Depression } & Chi Value & P- Value \\
& No & Yes & & \\
\hline Less than $70 \%$ & 3 & 26 & 4.730 & $0.030^{*}$ \\
$70 \%-80 \%$ & 14 & 38 & & \\
$80-90 \%$ & 7 & 12 & & \\
\hline
\end{tabular}

Chi Square test *significant at $\mathrm{p}<0.05$ 
It was found significant association between depression and academic performance of students. Therefore it can be concluded that the research hypothesis was accepted (Table 3)

Table 4:Total Score Analysis of Anxiety and Depression of Respondents.

\begin{tabular}{lll} 
& & \multicolumn{1}{c}{$\mathbf{n}=\mathbf{1 0 0}$} \\
\hline Statistics & Anxiety & Depression \\
\hline Mean ( \pm SD) & $13.15( \pm 6.06)$ & $13.82( \pm 6.88)$ \\
Median (IQR) & $12.50(9.00-15.00)$ & $13.00(10.00-17.00)$ \\
Range(Maximum - Minimum) & $32.00-1.00$ & $35.00-1.00$ \\
\hline
\end{tabular}

$\mathrm{IQR}=$ Interquartile Range

The study depicted that the total score analysis of anxiety and depression in which mean $( \pm \mathrm{SD})$ of anxiety was 13.15 ( \pm 6.06 ), median was 12.50 and range was 31 whereas the mean $( \pm$ SD) of depression was $13.82( \pm 6.88)$, median was 13.00 and range was 34 . We can conclude that the mean and median score of anxiety and depression were not equal. So the scores were not normally distributed (Table 4).

Table 5: Relationship between Total Depression and Total Anxiety Scores of Respondents.

\section{Relationship of scores}

$$
\mathrm{n}=\mathbf{1 0 0}
$$

$\begin{array}{cc}\text { Spearman's Rank Correlation } & 0.554 \\ \text { p-value } & 0.000\end{array}$

This study revealed the positive relationship between total depression and total anxiety score of respondents. It was found to be correlated with each other i.e. Spearman's rank correlation value was $0.554(\mathrm{p}=<0.05)$ (Table 5).

\section{Discussion}

The present study found anxiety among $10 \%$ of adolescent students. The study also found 59\% respondents had mild depression, $14 \%$ respondents had moderate depression, and 3\% had severe depression which is comparable with the study carried out in Iran, it has reported the prevalence of depression among high school students as follows: mild depression in 18\%, moderate depression in $9 \%$, and severe depression in 7\%, hence, a total rate of 34\%, Jafar et al [11].

The research hypothesis was that depression and anxiety would be significantly associated with low academic performance. The present study showed anxiety was not significantly associated with academic performance but depression was significantly associated with low academic performance $(\mathrm{p}=0.030)$ at $95 \%$ confidence interval which means those who have lower academic performance have higher level of 
depression. Research has indicated that depressed mood is negatively related to academic achievement carried out by Moosavi \& Fallahi [12]. It was also found consistent with literature.

The research hypothesis was that depression and anxiety would be significantly associated with low academic performance. The present study showed anxiety was not significantly associated with academic performance but depression was significantly associated with low academic performance $(p=0.030)$ at 95\% confidence interval which means those who have lower academic performance have higher level of depression. Maccoby \& Martin's study has indicated that depressed mood is negatively related to academic achievement [13].

The next hypothesis was depression and anxiety would be significantly associated with poor parent adolescent relationship. Parent- adolescent relationship is a strong bulwark for the adolescent during this delicate period of major changes in life. Among the variables conflict with father was significantly associated with the high level of anxiety of adolescents' i.e. P value was 0.019 . These variables were not significantly associated with depression of adolescents. Research has proved that warmth and control are thought to be the most important ways in which parents influence the development of their offspring or children as suggested by Lewinsohn et al. [14]. Depression in adolescence is often associated with the absence of supportive and positive interactions with parents and is characterized by elevated levels of conflictual, critical and angry interactions, Brady \& Kendall reported [15].

The most important part of this study was to test the correlation between depression and anxiety score. The hypothesis was, there would be positive relationship between depression \& anxiety score. The present study revealed that the relationship between total depression and total anxiety score of respondents was found to be remarkably correlated to each other i.e. Spearman's rank coefficient value was 0.554 which indicated that when anxiety was more, the depression level was also going up. It was founded that when degree of depression was more, the anxiety must be present which was coincide with the research findings indicates that there is considerable overlap between anxiety and depressive symptoms in youth, as measured by commonly used self-report questionnaires by Seligman \& Ollendick [16].

\section{Conclusion}

It can be concluded that Adolescent depression and anxiety are significant mental health problems. Many depressed and anxious students fail in school, develop interpersonal difficulties, and get in troubles with parent adolescent relationship. These also decrease motivation towards the ability for attention and concentration. Depression is an under-recognized yet a prevalent health problem among adolescents. It does not only cause suffering and loss of functional ability, but it also serves as a risk factor for suicidal attempts and numerous negative behaviors such as smoking, alcohol and drug use. Prevention and control activities focus on modifying and improving the psychosocial factors.

\section{Acknowledgement}

The author would like to express her gratitude to Tribhuvan University, Institute of Medicine, and Nursing Campus Maharajgunj. The author would like to express her heartfelt gratitude to NHRC for 
providing financial support which is the golden opportunity for post graduate student researcher. The author would like to thank Principal of Arniko Higher Secondary School at Biratnagar for giving permission and cooperation for this study. The author would like to express her heartfelt thanks to Professor Dr. Vidya Dev Sharma, Head of the Department, psychiatry for providing guidance for selection of topic and giving permission to use tool for data collection. The author would ever indebted to all adolescent students who consented and cooperated to become the part of this study.

\section{References}

[1] M. Laufer, Assessment of Adolescent disturbances, the application of Anne Freud's diagnostic profile, Psychoanalytic study of children, 20 (1965) 99-123.

[2[ R.G. Mayne, An Expository Lexicon of the Terms, Ancient and Modern, in Medical and General Science, London, Churchill Livingston (1860).

[3] World Health Organization, Strategies for Adolescent Health and Development, (1998).

[4] A. M. Albano, B.F. Chorpita, and D. H. Barlow, Journal of Abnormal Psychology 107 (1998) 74-85. https:/doi.org/10.1037/0021-843X.107.1.74

[5] J. H. Kashani, H. Orvaschel, American Journal of Psychiatry 147 (1990) 313-318. https:/doi.org/10.1176/ajp.147.3.313

[6] C. A. Essau, J. Conrad , F. Petermann, Journal of Anxiety Disorders 14 (2000) 263-279. https:/doi.org/10.1016/S0887-6185(99)00039-0

[7] D. D. Weiss, C.G. Las, Developmental Variations in the Prevalence and Manifestations of Anxiety Disorders, The Developmental Psychopathology of Anxiety: Oxford University Press (2001) pp.27-42.

[8] N. Hughes, Cognitive Behavior, Therapy of Children in Schools, New York: Pergamon Press, (1988) pp. $172-174$.

[9] A.T. Beck, G. Epstein, R.A. Steet, Journal of Consulting and Clinical Psychology 56 (6) (1967) 893.

https:/doi.org/10.1037/0022-006X.56.6.893

[10] A.T. Beck, C.H. Ward, M. Mendelson, J. J Mock, Archives of General Psychiatry 4 (1997) 561571.

https:/doi.org/10.1001/archpsyc.1961.01710120031004

[11] M. Jafar , M. Nia, H. Shodjai, S.R. Moosavi, N. Jahanbakhsh, M. Fallahi, Archives of Iranian Medicine 10 (2) (2007) 141 - 146

[12] S.R. Moosavi, M. A. Fallahi, Archives of Iranian Medicine 10 (2) (2006) 141 - 146.

[13] E. E. Maccoby, J. A. Martin, Socialization in the context of the family: Parent child interaction. Handbook of Child Psychology: Socialization, personality, and Social development 4 (1986)1-101.

[14] P.M. Lewinsoh, P. Rohde J.R. Seeley, Journal of Abnormal Psychology 107 (1998) 74-85.

[15] E.U. Brady, P. C. Kendall, Psychological Bulletin 111 (1992) 244-255. https:/doi.org/10.1037/0033-2909.111.2.244

[16] L. D. Seligma, T. H. Ollendick, Clinical Child and Family Psychology Review 1 (1998) 125-144. https:/doi.org/10.1023/A:1021887712873 